\title{
Expression of PKC Iota Affects Neuronal Differentiation of PC12 Cells at Least Partly Independent of Kinase Function
}

\author{
Alana Doonachar, Alan R. Schoenfeld* \\ Department of Biology, Adelphi University, Garden City, USA \\ Email: ${ }^{*}$ schoenfeld@adelphi.edu
}

Received 1 January 2014; revised 1 February 2014; accepted 8 February 2014

Copyright (C) 2014 by authors and Scientific Research Publishing Inc.

This work is licensed under the Creative Commons Attribution International License (CC BY). http://creativecommons.org/licenses/by/4.0/

\begin{abstract}
Atypical PKC (aPKC) plays a role in establishing cell polarity and has been indicated in neuronal differentiation and polarization, including neurite formation in rat pheochromocytoma PC12 cells, albeit by unclear mechanisms. Here, the role of the aPKC isoform, PKC iota (PKC ), in the early neuronal differentiation of PC12 cells, was investigated. NGF-treated PC12 cells with stably expressed exogenous wild-type PKCı showed decreased expression of a neuroendocrine marker, increased expression of a neuronal marker and increased neurite formation. Stable expression of a kinase-inactive PKCt, but not constitutively active PKCı lacking a regulatory domain, had similar though less potent effects. Pharmacological inhibition of endogenous aPKC kinase activity in parental PC12 cells did not inhibit neurite formation, suggesting that some of the observed effects of PKC expression of wild-type and kinase-inactive PKC caused a decrease in PKC zeta (PKC) kinase activity, suggesting an interplay between the two isoforms that may underlie the observed results. Overall, these findings suggest that in PC12 and perhaps other neuroendocrine precursor cells, PKCı influences an early differentiation decision between the neuroendocrine (chromaffin) and sympathetic neuron cell lineages, potentially by affecting PKC function.
\end{abstract}

\section{Keywords}

Atypical PKC; Neurite Outgrowth; Neuronal Differentiation; Neuroendocrine; PC12; PKC Iota

${ }^{*}$ Corresponding author. 


\section{Introduction}

Protein kinase C (PKC) is a family of kinases that are involved in regulation of target proteins through the phosphorylation of their serine and/or threonine amino acid residues. PKCs are conserved among eukaryotes and play important roles in several signal transduction cascades. The PKC family consists of at least ten isozymes that are divided into three subfamilies based on their structure and activation mechanisms: conventional, novel and atypical [1]. All PKC isoforms have a highly conserved C-terminus kinase domain and an N-terminal regulatory domain containing a pseudosubstrate region, however, the regulatory region varies among family members (reviewed in [2] [3]). Whereas classical and novel PKCs have a calcium-dependent phospholipid binding (C2) domain and a tandem zinc-finger (C1) domain in their regulatory region, atypical PKCs (aPKCs) lack a C2 domain and have only one $\mathrm{C} 1$ domain and thus do not depend on calcium or diacylgycerol for activation (reviewed in [1]-[3]). One important activation mechanism for activation of aPKCs includes allosteric activation via the interaction of the PAR-6-CDC42 complex to the PB1 (Phox and Bem 1) domain, which among PKCs is found only in aPKCs (reviewed in [2]).

There are two isoforms of aPKC, PKC iota (PKC1, named PKC $\lambda$ in mice) and PKC zeta (PKC)). aPKC is important for maintaining polarity in cells [4], which is necessary for a range of normal cellular functions including asymmetric cell division, cell-cell contact, proper maintenance of epithelial cell integrity and cell migration [3]. An aPKC role in establishing and maintaining polarity has been suggested to be important for the development and differentiation of neurons [5], for which axon formation represents an extreme example of cell polarization. During the beginning of axon formation, a complex of aPKC, PAR-3, PAR-6 and a Rac-specific guanine nucleotide exchange factor, mediates the activation of Rac, which controls actin polymerization in elongating axon [6]. Localization of PAR-3 to the tip of the developing axon is especially important for this process [7]. While it is clear that aPKC and its associated complexes are needed for this later stage of neuronal differentiation, it is currently unclear what role aPKC plays at the earlier steps of neuronal differentiation, particularly at the time when multipotent precursor cells decide to differentiate along the neuronal lineage.

Toward further examining the roles of aPKC in early neuronal differentiation, we have employed the rat PC12 pheochromocytoma cell line as a model system. PC12 cells represent a cell type with both neuroendocrine and neuronal differentiation potential, as they both secrete catecholamines and upon NGF treatment, form neurites indicative of early neuronal differentiation [8]. In this study, we have exogenously expressed either wild-type $\mathrm{PKCl}$ or constitutively active (catalytic domain, lacking the regulatory domain) or kinase-inactive mutants of $\mathrm{PKC}$ [9] in PC12 cells and analyzed their effects on the neuroendocrine and neuronal characteristics of these cells.

\section{Materials and Methods}

\subsection{Cell Culture}

PC12 and 293T cell lines were obtained from the American Type Culture Collection. PC12 cells were grown in Dulbecco's modified Eagle's medium (DMEM), supplemented with 10\% heat-inactivated horse serum, 5\% heat-inactivated fetal bovine serum, and $1 \%$ penicillin-streptomycin ( $100 \mathrm{U} / \mathrm{ml}$ and $10 \mu \mathrm{g} / \mathrm{ml}$, respectively).

\subsection{PKCı Retroviral Expression Vectors, Retroviral Production and Infection}

Plasmids directing expression of HA-tagged wild-type (WT) and constitutively active catalytic domain (CAT) and kinase-inactive (KI) mutants of PKCi [10] were generously provided by Dr. Jae-Won Soh (Inha University, Korea). The HA-PKCı coding sequences of these plasmids were excised with XhoI and NotI restriction enzymes and subcloned into a pLNCX2 retroviral expression vector that had been similarly cut. To produce retroviral supernatants, the recombinant retroviral vectors were co-transfected with the retroviral packing plasmid, pCLAmpho [11], into 293T cells, as previously described [12]. To create stable pools of retrovirally-infected PC12 cells, PC12 cells were incubated overnight in a mixture (1:1) of each retroviral supernatant and fresh medium supplemented with polybrene $(10 \mu \mathrm{g} / \mathrm{ml})$ and then replaced with fresh PC12 media the next day. Three days later, the cells were incubated in media containing G418 $(1 \mathrm{mg} / \mathrm{ml})$ to allow for proper selection of the cells expressing the desired PKCı.

\subsection{Western Blotting}

PC12 cell lines grown on 60-mm culture dishes until confluent were rinsed with PBS and then lysed by incubat- 
ing with $150 \mu \mathrm{l}$ of lysis buffer (50 mM HEPES (pH 7.6), $250 \mathrm{mM} \mathrm{NaCl}, 0.5 \%$ Nonidet P-40, 0.5\% Triton X-100, $5 \mathrm{mM}$ EDTA, $1 \mathrm{mM}$ phenylmethylsulfonyl fluoride (PMSF), $1 \mathrm{mM} \mathrm{Na} 2 \mathrm{VO} 3$ and $2 \mu \mathrm{g} / \mathrm{ml}$ each of aprotinin, bestatin, and leupeptin) at $4^{\circ} \mathrm{C}$ for 30 minutes. Lysed cells were scraped with a plastic scraper, resuspended by pipetting, collected, and were spun down in a refrigerated microcentrifuge for 15 minutes to remove all insoluble material. The supernatant was collected and a Bradford protein assay (Bio-Rad, Hercules, CA) was performed to determine protein concentrations. Equal amounts of protein for each well of a gel, ranging from 25 $50 \mu \mathrm{g}$ among the different blots performed, were mixed with an equivalent volume of $2 \times$ SDS buffer and were separated by SDS-PAGE. The separated proteins were then transferred to a polyvinylidene difluoride (PVDF) membrane overnight at 30 volts for 16 hours and western blotting was then performed as described [12].

\subsection{Antibodies}

Mouse monoclonal antibodies: Anti- $\beta 1$ integrin antibody from BD Biosciences (Franklin Lakes, NJ) and anti- $\alpha$ tubulin from Sigma (St. Louis, MO) were used at a 1:1000 dilution in western blots. Rabbit polyclonal antibodies: Anti-HA antibody from Santa Cruz Biotechnology (Santa Cruz, CA) was used at a 1:200 dilution in western blots. Anti-PKC1, anti-PKC $\zeta$, anti-Tyrosine Hydroxylase and anti-MAP2 antibodies from Cell Signaling Technology (Danvers, MA), anti-PAR-6B from Sigma (St. Louis, MO) and anti-PAR-3 and anti-phosphoserine from EMD Millipore (Billerica, MA) were used at 1:1000 and 1:500 dilutions, respectively in western blots. Secondary antibodies were anti-mouse IgG-HRP and anti-rabbit IgG-HRP (Sigma, St. Louis, MO) used at a 1:2286 dilution.

\subsection{Immunoprecipitations}

Cells grown to confluence in 100-mm culture dishes were rinsed with PBS and lysed as described for western blot lysate preparation. For each HA immunoprecipitation, $25 \mu \mathrm{l}$ of monoclonal HA-agarose beads (Sigma, St. Louis, MO) was used. Beads were washed 3 times with PBS and once with lysis buffer, resuspended in lysis buffer and incubated with $500 \mu g$ of lysate for 3 hours with rotation at $4^{\circ} \mathrm{C}$. Immune complexes were washed four times with lysis buffer and eluted by incubating with $30 \mu \mathrm{l}$ of $2 \times$ SDS gel loading buffer, which was then heated to $55^{\circ} \mathrm{C}$ for 3 minutes. $10 \mu \mathrm{l}$ of the eluted immunoprecipitates was loaded on one SDS page gel (for HA western blotting), whereas the remaining $20 \mu \mathrm{l}$ was loaded onto another gel (for PAR-6B and PAR-3 western blotting). Proteins were separated by SDS-PAGE and visualized by Western blotting. Quantification of bands was performed from scans of the western blots using Image J (version 1.42q). PAR-3 immunoprecipitations were performed similarly except that lysates were supplemented with $0.5 \%$ sodium deoxycholate and incubated with $1.5 \mu \mathrm{l}$ of PAR-3 antibody for 1 hour. $20 \mu \mathrm{l}$ of Protein G Sepharose 4 Fast Flow (GE Healthcare Biosciences, Pittsburgh, PA) was added incubated for another hour. Immune complexes were washed as above, except that 40 $\mu \mathrm{l}$ of $2 \times$ SDS gel loading buffer was used, which were then divided into 2 aliquots to be loaded into different lanes.

\subsection{Neurite Outgrowth Assays}

Wells from a 6-well plate were covered with $0.5 \mathrm{ml}$ of a $20 \mu \mathrm{g} / \mathrm{ml}$ solution of laminin (Sigma), which was allowed to dry. Each cell line was plated in triplicate wells at an initial density of $1 \times 10^{4}$ cells per well and allowed to attach for 24 hours. Each cell line was then incubated for a period of 48 hours in serum-free DMEM that was supplemented with $100 \mathrm{ng} / \mathrm{ml}$ of NGF (nerve growth factor, Becton Dickenson). Images of these cell lines at 48 hours post-treatment with NGF were captured using a Zeiss Axiovert S100 inverted microscope equipped with a Nikon digital camera with NIS-elements F 2.20 digital-imaging software. In all analyses, neurites that were counted were neuron-like extensions of the cell membrane that were equal to or longer than twice the diameter of the cell. Student's t-tests were performed to determine statistical significances with respect to control cells. To analyze neurite outgrowth after PMA treatment, cells were treated as previously described, except they were allowed to adhere for 3 - 5 hours and then treated with phorbol 12-myristate-13-acetate (PMA, 1 $\mu \mathrm{M})$ for two days prior to NGF treatment. The PMA was removed, and the cells were then treated with NGF $(100 \mathrm{ng} / \mathrm{ml})$ in serum-free media and imaged after 48 hours, as previously. To analyze the effects of PKC inhibitors on neurite outgrowth, parental PC12 cells were treated as previously described, except media containing serum was used during the NGF incubation. The PKC inhibitor, Gö6983 (200 nM), was added to certain wells at 
the same time as NGF, and the cells were imaged after 48 hours, as previously.

\subsection{PKC Kinase Activity Assay}

PC12 cell lines grown to near-confluence on laminin-coated 100-mm culture dishes were incubated with NGF $(100 \mathrm{ng} / \mathrm{ml})$ in serum-free media for 1 day and subjected to either $\mathrm{PKCl}$ or $\mathrm{PKC} \zeta$ immunoprecipitation. Briefly, cells were lysed as described above and $500 \mu \mathrm{g}$ of each lysate was incubated at $4^{\circ} \mathrm{C}$ with $2 \mu \mathrm{g}$ of either anti$\mathrm{PKC} \imath$ or $\mathrm{PKC} \zeta$ antibody for 1 hour with rotation. Immune complexes were captured by incubating with $20 \mu \mathrm{l}$ of pre-rinsed Protein G Sepharose 4 Fast Flow (GE Healthcare Biosciences, Pittsburgh, PA) for 1 hour at $4^{\circ} \mathrm{C}$ with rotation. The Sepharose beads with immunoprecipitated $\mathrm{PKCl}$ or $\mathrm{PKC} \zeta$ were then washed four times with lysis buffer and incubated with $25 \mu \mathrm{l}$ of PKC reaction mixture from the PepTag Non-Radioactive Protein Kinase C Assay (Promega, Madison WI). The assay was carried out as directed by the manufacturer, except that $20 \mu \mathrm{l}$ of the reaction was separated on a $0.6 \%$ agarose gel to resolve the fluorescent phosphorylated and unphosphorylated PKC substrates. Images were captured on a FOTO/Analyst Investigator gel documentation workstation (Fotodyne, Hartland, WI) and band intensities were quantified using Image J software (version 1.47). After the reaction mixture was removed and separated, the beads and the remaining $5 \mu \mathrm{l}$ of reaction mixture were incubated with $30 \mu \mathrm{l}$ of $2 \times$ SDS gel loading buffer, which was then heated to $55^{\circ} \mathrm{C}$ for 3 minutes, separated by SDSPAGE, and subjected to PKC $\zeta$ western blotting.

\section{Results}

\subsection{Exogenous (But Not Overexpressed) PKC $\iota$ Decreases Neuroendocrine Characteristics of PC12 Cells}

PC12 cell lines stably expressing exogenous HA-tagged versions of either wild-type (WT) $\mathrm{PKC} \mathrm{r}$ or kinase-inactive (KI) and constitutively active catalytic domain (CAT) mutants of $\mathrm{PKC} \mathrm{t}$ were created. To test for proper expression of these proteins, an HA western blot was performed (Figure 1, top panel). Bands for HA-tagged $\mathrm{PKC \imath} \mathrm{KI}, \mathrm{PKCl} \mathrm{WT}$, and $\mathrm{PKC \imath} \mathrm{CAT}$ were observed at the appropriate molecular masses. $\mathrm{PKC \imath} \mathrm{CAT}$ was less abundant when compared to $\mathrm{PKCl} \mathrm{KI}$ and WT, perhaps because the $\mathrm{PKCl}_{\imath} \mathrm{CAT}$ protein is truncated (lacking the regulatory domain), which may affect the $\mathrm{PKC}$ protein's stability. To determine the extent of overexpression of

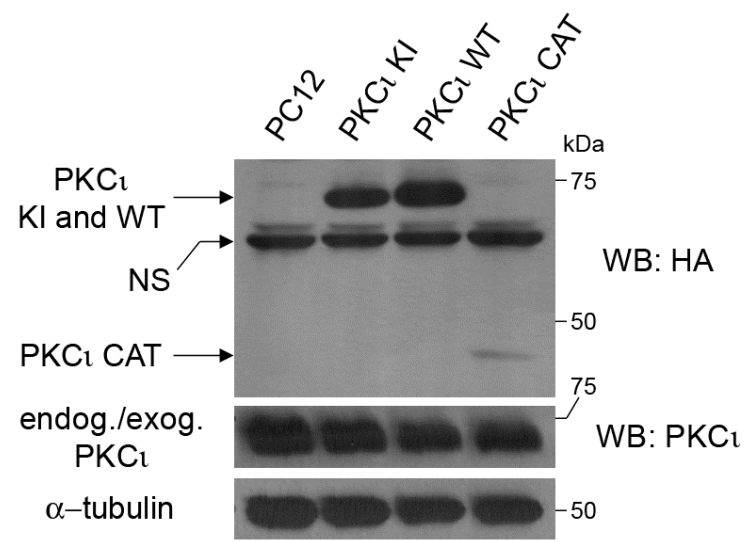

Figure 1. Creation of PC12 cell lines stably expressing PKC1. PC12 cells were stably infected with retroviruses directing expression of HA-tagged wild-type (WT) PKCı and kinaseinactive (KI) and constitutively active catalytic domain (CAT) mutants. Lysates from indicated cell lines grown to confluence were equally loaded and separated by SDSPAGE. Lane 1 contains lysate from uninfected cells as a control. Western blots were performed using a rabbit anti-HA antibody (top panel), anti $\mathrm{PKCl}$ antibody (middle panel), and anti- $\alpha$-tubulin antibody. NS indicates a non-specific band that appears in the top panel. 
the $\mathrm{PKC}_{\imath}$ in these cell lines, a western blot was performed using a $\mathrm{PKC} \mathrm{l}$ antibody that detects both endogenous and exogenous $\mathrm{PKCl}$ (Figure 1, middle panel). Interestingly, no major difference in $\mathrm{PKCl}$ levels was observed as compared to the parental cell line. Hence, there was no gross overexpression of the HA-tagged proteins.

The PC12 cell lines were analyzed for levels of neuroendocrine and neuronal markers. Decreased levels of tyrosine hydroxylase, the rate-limiting enzyme for catecholamine production and marker for the catecholaminergic phenotype [13], were observed in the PKCı WT cell line when compared to the other PC12 cell lines (Figure 2, third panel). Expression levels of the sympathetic neuron marker, microtubule-associated protein 2 (MAP2) [14], were fairly similar in all four cell lines (Figure 2, top two panels). Levels of $\beta 1$ integrin, which have been correlated to the ability of PC12 cells to extend neurites on laminin in response to nerve growth factor (NGF) [15], were also somewhat decreased in the PKCı WT cell line when compared to the other PC12 cell lines (Figure 2, bottom panel). Thus, exogenously expressed PKCı WT had a negative effect on the abundance of both tyrosine hydroxylase and $\beta 1$ integrin.

\subsection{Exogenous Wild-Type and, to a Lesser Extent, Kinase-Inactive PKCı Increase Neuronal Characteristics and Neurite Formation of NGF-Treated PC12 Cells}

To determine whether PKCı WT affects the ability of PC12 cells to form neurites upon NGF exposure [8], a neurite outgrowth assay was performed (Figure 3). Based on the down-regulation of $\beta 1$ integrin, it was expected that the PKCi WT cell line would show a decreased ability to form neurites. Surprisingly, both the PKCi WT and $\mathrm{PKC \imath} \mathrm{KI}$ cell lines, but not the $\mathrm{PKC \imath} \mathrm{CAT}$ cell line, demonstrated a statistically significant increase in the percent of cells that were positive for neurite outgrowth as compared to parental PC12 cells (Figure 3(a)). It was also noted that the $\mathrm{PKCr}$ WT cell line had a significantly more overall neurites (per cell) than the control line (Figure 3(b) and representative picture in Figure 3(c)), which suggests that its effects are slightly more potent than that of $\mathrm{PKCl} \mathrm{KI}$. The presence of multiple long neurites due to $\mathrm{PKC \imath} \mathrm{WT}$ (and to a lesser extent $\mathrm{PKCl} \mathrm{KI}$ ) expression may indicate that the early steps of neuronal polarization are being affected [16], although it is unclear from these results whether polarization is being enhanced or inhibited.

Because differences in the NGF-mediated neurite outgrowth were observed with the $\mathrm{PKC}_{1} \mathrm{WT}$ and $\mathrm{PKC \imath} \mathrm{KI}$ cell lines, the effect of expression of these proteins on neuronal and catecholaminergic markers was readdressed, focusing on changes that occur after NGF exposure. Thus, the cell lines were treated with NGF for 5 days and western blots were performed (Figure 4). Under these conditions, MAP2 A/B isoforms, which have been linked to neuronal differentiation [17], were observed to be more abundant in the NGF-treated $\mathrm{PKC \imath}$ WT and $\mathrm{PKC} \mathrm{KI}$ cell lines (Figure 4, upper panel). Levels of the upper band of MAP2 C/D, MAP2 D, were also increased (Figure 4, second panel). This observation is in accord with the necessity of MAP2 for neurite establishment and

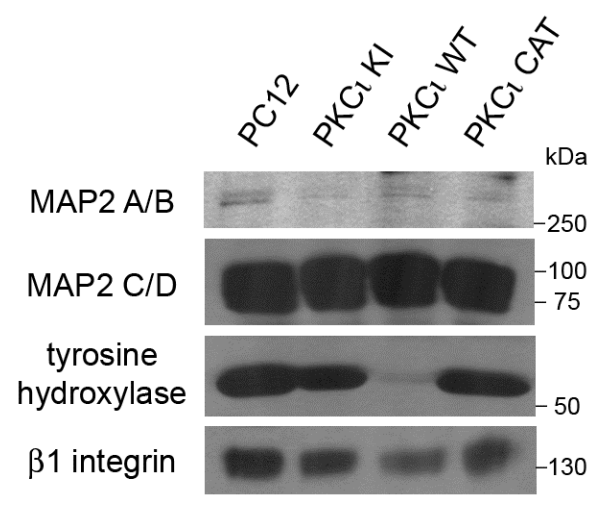

Figure 2. Exogenous expression of kinaseinactive $\mathrm{PKC} \mathrm{r}$ decreases levels of certain neuronal markers. Lysates from indicated cell lines grown to confluence were equally loaded and separated by SDS-PAGE. Western blots were performed using antibodies to MAP2 (top panels), tyrosine hydroxylase (lower middle panel), and $\beta 1$ integrin (lower panel). 
(a)

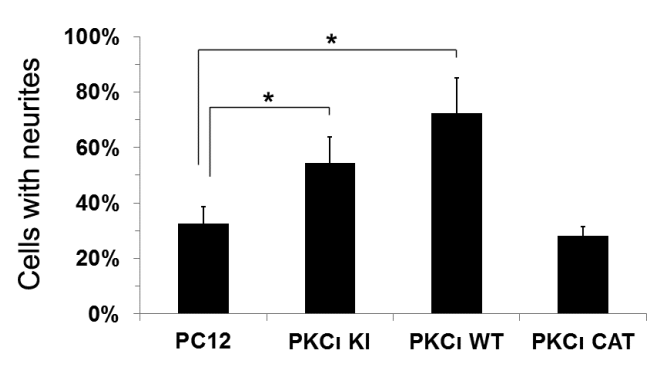

(c)

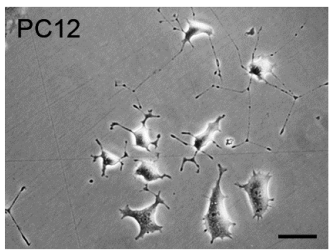

(b)

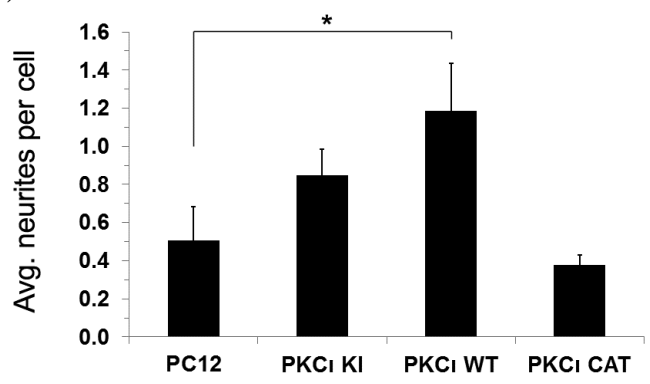

Figure 3. Exogenous expression of either kinase-inactive or wild-type $\mathrm{PKC}$ increases neurite outgrowth, with wild-type PKCı having the greatest effect. Indicated PC12 cell lines were plated on laminin-coated plates, and then treated with nerve growth factor (NGF) for 2 days. (a) The percentage of cells positive for neurites (displaying a neurite at least 2 times the body length was determined for each cell line) was determined for each cell line. *indicates statistically significant differences $(P<0.05)$. (b) The total number of neurites per cell that were at least 2 times the cell diameter was determined for each cell line. (c) Representative pictures of the neurite growth assays for each cell line are presented. The scale bars in the lower right corner or each picture represent $200 \mu \mathrm{m}$.

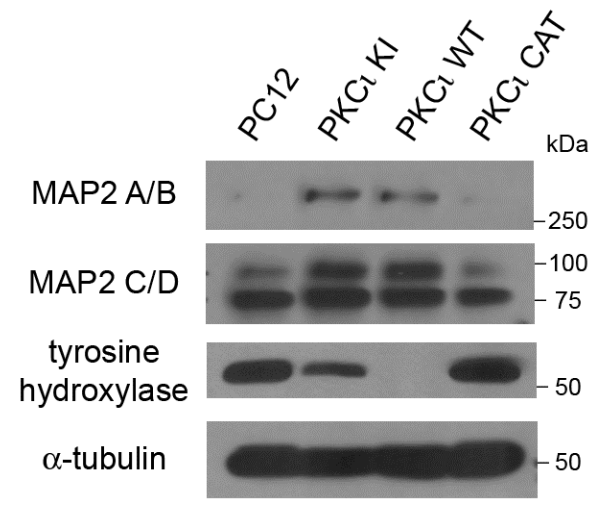

Figure 4. Increased MAP2 A/B expression is revealed in cells exogenously expressing kinase-inactive or wild-type $\mathrm{PKCl}$ after NGF treatment. The indicated PC12 cell lines were incubated in media containing NGF (100 $\mathrm{ng} / \mathrm{ml}$ ) for 5 days and then lysed. Lysates were equally loaded and separated by SDSPAGE. Western blots were performed using antibodies to MAP2 (top panels), tyrosine hydroxylase (lower middle panel), and $\alpha$-tubulin (bottom panel).

maintenance [18] [19]. Tyrosine hydroxylase was dramatically decreased in the PKCı WT cell line and was also slightly decreased in the $\mathrm{PKC \imath} \mathrm{KI}$ cell line after NGF treatment (Figure 4, third panel). Thus, these results suggest that exogenous expression of $\mathrm{PKCl}_{\mathrm{WT}}$ or, to a lesser extent, $\mathrm{PKCl} \mathrm{KI}$ suppresses neuroendocrine characteristics (i.e., tyrosine hydroxylase expression) and increases neuronal characteristics (i.e., MAP2 and neurite out- 
growth) of PC12 cells in the presence of NGF. Given that PC12 cells behave like a progenitor cell that can differentiate along either the chromaffin cell lineage or that of sympathetic neurons [8], the present findings suggest that expression of $\mathrm{PKCl}$ can influence this choice of lineage.

\subsection{Neurite Outgrowth Can Occur Independently of aPKC Kinase Activity}

Previous studies have reported that aPKC is necessary for neurite outgrowth in PC12 cells [20] [21]. Since expression of both the wild type and kinase-inactive forms of $\mathrm{PKC} \mathrm{C}$ had effects on neurite formation with our cell systems, corroboration that aPKC function is necessary for neurite outgrowth was sought. Long-term phorbol 12-myristate-13-acetate (PMA) treatment has been shown to cause depletion of the PMA-sensitive classical and novel PKCs, but not atypical PKC [20]. Thus, our PC12 cell lines were treated with PMA for two days to deplete classical and novel PKCs, after which the PMA was removed and a neurite outgrowth assay was performed. Again, statistically significant increases in neurite outgrowth in the $\mathrm{PKC \imath} \mathrm{KI}$ and WT cell lines were seen when compared to the PC12 parental cell line (Figure 5(a)). This implies that novel and classical PKCs are not involved in neurite outgrowth and that the effect of expression of PKCı WT and $\mathrm{KI}$ on this process is not mediated through effects on the PMA-sensitive PKCs.

To further assess the role of aPKC function in neuritogenesis, neurite outgrowth assays were also performed on the parental PC12 cells in the presence of a PKC inhibitor (Figure 5(b)). Gö6983 has been reported to suppress the kinase activity of PKC novel and conventional PKC isotypes $\alpha, \beta, \gamma, \delta$ with an IC50 at or under $10 \mathrm{nM}$ and the atypical PKC $\zeta$ with an IC50 of $60 \mathrm{nM}$ [22]. Treatment of PC12 cells with $200 \mathrm{nM}$ Gö6983, which should inhibit aPKC, had no significant effect on neurite outgrowth. To confirm that aPKC was inhibited under the conditions used in this assay, phosphorylation of PAR-3, an aPKC substrate [23], was indeed observed to be

(a)

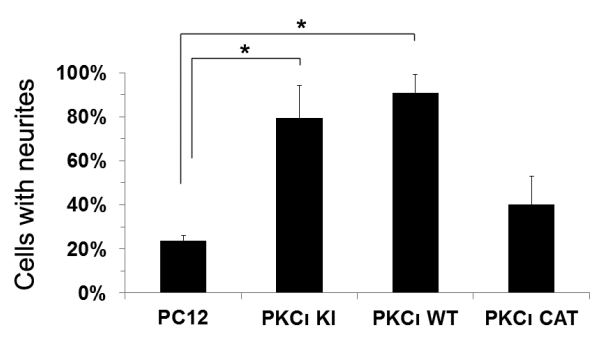

(b)

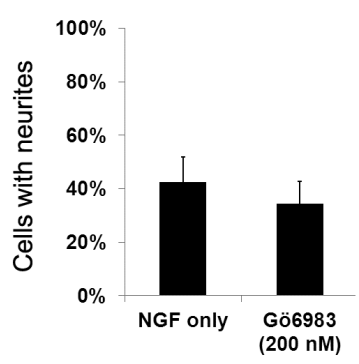

(c)

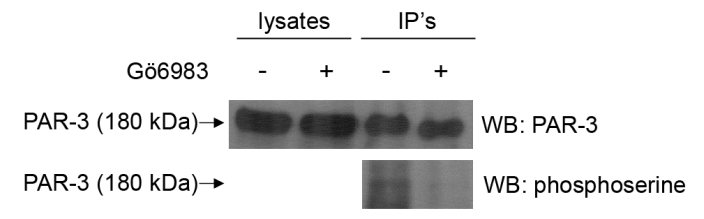

Figure 5. Neurite outgrowth can occur independently of aPKC kinase activity. (a) Indicated PC12 cell lines were treated with PMA for 2 days and then a neurite outgrowth assay was performed as previously, using NGF. The percentage of cells positive for neurites (displaying a neurite at least 2 times the body length) was determined for each cell line. *indicates statistically significant differences $(\mathrm{P}<0.05)$. (b) Parental PC12 cells were treated with NGF only or with NGF plus the PKC inhibitor Gö6983 (200 nM). The percentage of cells positive for neurites was determined for each treatment. *indicates statistically significant differences $(\mathrm{P}<$ 0.05). (c) Parental PC12 cells were prepared as in (B) and then PAR-3 was immunoprecipitated. Half of the eluted immune complexes were loaded onto two lanes of a 6\% SDS-PAGE gel for PAR-3 western blotting (top panel) and the remaining half of eluates were loaded on the same gel for phosphoserine western blotting (bottom panel). The lysates, representing $1 / 25^{\text {th }}$ of the amount of lysate used for immunoprecipitation, were also separated to the left of one set of eluates. After transfer, the membrane was sliced vertically to perform the PAR-3 and phospho- serine western blots. 
inhibited by the $200 \mathrm{nM}$ Gö6983 treatment (Figure 5(c)). Overall, these results suggest that classical and novel $\mathrm{PKC}$ isotypes are not necessary for neurite formation and imply that functions of $\mathrm{PKCl}$ additional to its kinase activity are involved in its effect on neurite outgrowth. Note that in previous studies, removal of aPKC protein (via antisense) caused a decrease in neurite outgrowth [21], which may seem to contradict our observed lack of effect on neurite outgrowth during aPKC inhibition. However, our assay differs in that aPKC proteins were still present, but the PKC kinase activity was inhibited. Thus, it may be that the expression of aPKC, and not necessarily its kinase activity, is sufficient to affect neurite outgrowth.

\subsection{Both Kinase-Inactive and Wild-Type Exogenous PKCı Bind to PAR-6B and PAR-3 in Cells}

Since aPKC kinase activity was seemingly dispensable for increased neurite and neuronal differentiation, we sought to identify non-kinase functions of aPKC that may play a role in some of the observed phenomena. aPKC proteins are known to participate in multiprotein complexes and can influence the activities and localization of the constituents of these complexes. One important member of such multiprotein aPKC complexes is the protein, PAR-6 [24]. In an effort to detect whether PKCı WT and KI, but not PKCı CAT, are able to bind to PAR-6, a co-immunoprecipitation assay was performed (Figure 6). PAR-6A, one of four isoforms of PAR-6, was not detectable in PC12 cells (data not shown). Therefore, the presence of another isoform, PAR-6B, was analyzed in aPKC immunoprecipitates. Indeed, both $\mathrm{PKC}_{1} \mathrm{KI}$ and WT, but not $\mathrm{PKC} \_\mathrm{CAT}$, showed a robust interaction with PAR-6B. The preferential binding of PAR-6B to $\mathrm{PKCl}$ WT and $\mathrm{KI}$ versus $\mathrm{PKCl} \mathrm{CAT}$ is somewhat expected since PAR-6 binds near the N-terminal of aPKC [24], which is present in these proteins, but absent in $\mathrm{PKCl}$ CAT [24]. PAR-3, which can form a ternary complex with aPKC and PAR-6 [25] [26], was also found in PKCı KI and WT immunoprecipitates, albeit to a lesser extent. We estimate, based on quantitation of western blot bands (data not shown), that 10-fold more PAR-6 than PAR-3 was co-immunoprecipitated with PKCi KI and WT. Cdc42, which can be a member of a quaternary complex with aPKC, PAR-6 and PAR-3 [25], was not detected in aPKC immune complexes (data not shown).

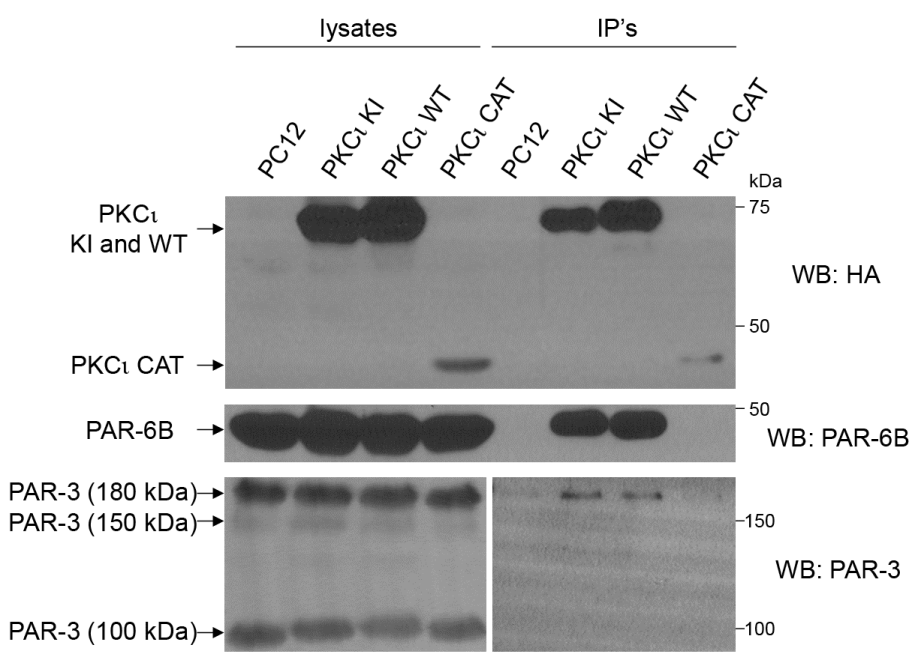

Figure 6. Both wild-type and kinase-inactive $\mathrm{PKCl}$ bind to PAR-6B and PAR-3 in cells. Indicated PC12 cell lines were lysed. Co-immunoprecipitation assays were performed by incubating lysates with anti-HA-agarose beads. Immune complexes were eluted and $1 / 3$ of the eluate was loaded onto one gel for HA western blotting (top panel) and the remaining $2 / 3$ of eluate was loaded onto a second gel for PAR-6B western blotting (middle panel). The lysates, representing $1 / 20$ th of the amount of lysate used for immunoprecipitation, were also separated on the left half of the gels, with immune complexes separated on the right side of the gels. The procedure was repeated for PAR-3 co-immunoprecipitation assay (bottom panels), except a lighter exposure was used to show PAR-3 in lysates (bottom left panel). 


\subsection{Expression of Exogenous PKCı Down-Regulates PKCろ Kinase Activity}

In order to determine whether expression of exogenous $\mathrm{PKCl}$ WT and $\mathrm{KI}$ have an effect on the kinase activity of endogenous $\mathrm{PKCl}$ that may underlie some of the observed effects on neuronal differentiation, a nonradioactive $\mathrm{PKC}$ assay was utilized. Both endogenous and exogenous $\mathrm{PKCl}$ were immunoprecipitated from our set of $\mathrm{PC} 12$ cell lines (which were grown on laminin and treated with NGF) and PKC kinase activity in the immune complexes was determined, as has been done by others [27]. $\mathrm{PKCl}$ activity was seen in immunoprecipitations from all of the cell lines, with only slight decreases in PKC activity observed in PKCı WT and CAT expressing cell lines as compared to control (Figures 7(a) and (b)). The observed differences may be attributable to lower levels of immunoprecipitated protein for $\mathrm{PKC \imath}$ WT and CAT, as seen in the middle panel (Figure 7(a)). The PKCi kinase activity in the $\mathrm{PKCl} \mathrm{KI}$ cell line was not significantly diminished as compared to the control line. Given the lack of parallel of these results with the observed pro-neuronal effects seen in this study with expression of $\mathrm{PKCl} \mathrm{WT}$ and $\mathrm{KI}$, it is unlikely that an effect of these exogenous proteins on endogenous $\mathrm{PKCl}$ activity underlies their pro-neuronal effects.

In order to see whether expression of $\mathrm{PKCl}$ affected the kinase activity of the other aPKC isoform, $\mathrm{PKC}$, in these cells, the experiment was repeated, except $\mathrm{PKC} \zeta$ was immunoprecipitated from the cells and assayed as above. Surprisingly, the PKC kinase activity of immunoprecipitated $\mathrm{PKC} \zeta$ was greatly diminished in both $\mathrm{PKCl}$ WT and PKCı KI cell lines (Figures 7(c) and (d)), with $\mathrm{PKC \imath}$ WT showing the greatest effect. Since the decrease in overall $\mathrm{PKC} \zeta$ activity mirrors the cell lines that had increased pro-neuronal effects, it is likely that this decrease in $\mathrm{PKC} \zeta$ activity plays a role in the increase in neurite formation and neuronal characteristics observed with the PKCı WT and KI cell lines.

(a)

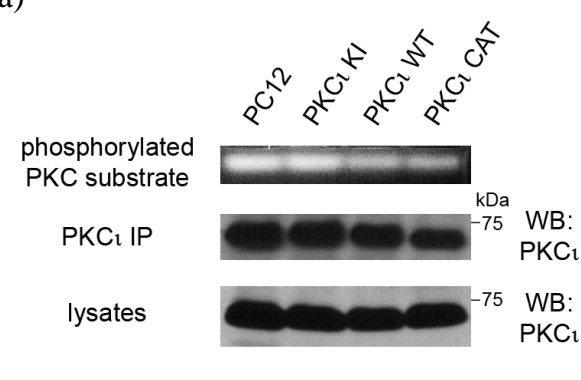

(c)

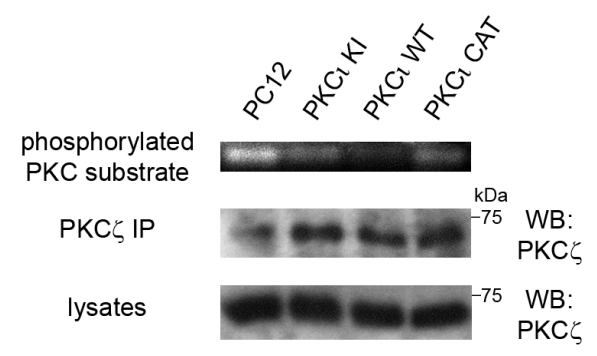

(b)

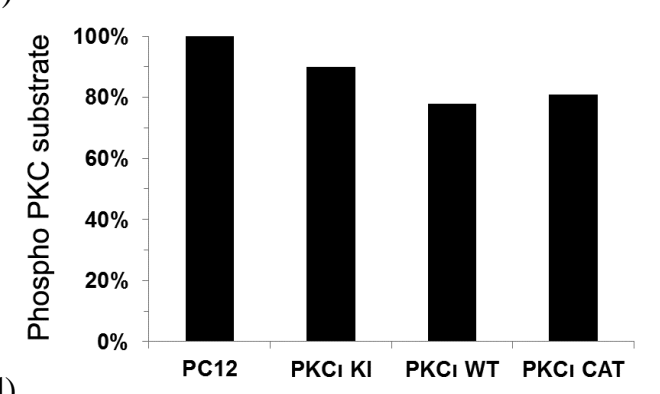

(d)

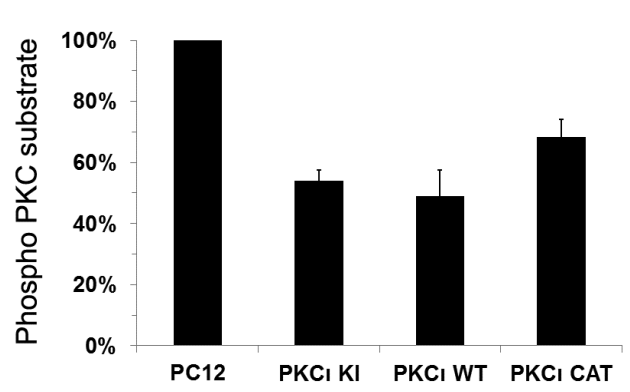

Figure 7. Expression of exogenous $\mathrm{PKCl}$ down-regulates $\mathrm{PKC} \zeta$ kinase activity. The set of PC12 cell lines were grown on laminin-coated culture dishes and incubated in serum-free media containing NGF (100 ng/ml) for 1 day and then lysed. Lysates were immunoprecipitated with antibodies to $\mathrm{PKCl}$ (in A) or PKC $\zeta$ (in (c)) and the beads containing the immune complexes were tested using the PepTag Non-Radioactive Protein Kinase C Assay (Promega, Madison WI). (a) and (c) Fluorescent bands corresponding to the phosphorylated PKC substrates (indicative of PKC kinase activity) for one representative assay are shown in the top panel. The immunoprecipitated $\mathrm{PKCl}$ (in $\mathrm{A}$ ) or $\mathrm{PKC} \zeta$ (in (c)) is

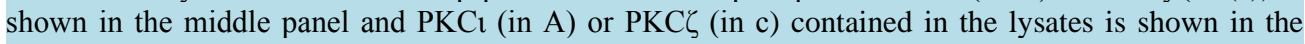
bottom panel. (b) and (d) Graphical representation of the PKC kinase assays in a and c, respectively, are shown. For d, the average of two separate PKC kinase assays is shown. Bars represent the percentage of phosphorylated PKC substrate as compared to the control assay performed with parental PC12 cells (in first column), which was set to $100 \%$. 


\section{Discussion}

In this paper, the role of $\mathrm{PKCl}_{1}$ in $\mathrm{PC} 12$ differentiation was investigated by expressing wild-type $\mathrm{PKC} \mathrm{l}$ and kinase-inactive and constitutively active (catalytic domain) mutants of $\mathrm{PKCl}$ in $\mathrm{PC} 12$ cells. Expression of wildtype $\mathrm{PKCl}$ and kinase-inactive $\mathrm{PKCl}$ suppressed neuroendocrine characteristics of $\mathrm{PC} 12$ cells and promoted neuronal differentiation in a manner that partly did not depend on $\mathrm{PKCl}$ kinase activity. However, expression of these proteins did negatively affect $\mathrm{PKC} \zeta$ kinase activity in NGF-treated cells. The present findings suggest that expression of $\mathrm{PKCl}$ can influence the choice of differentiation of PC12 cells between the neuroendocrine (chromaffin) and sympathetic neuron lineages, potentially through effects on PKC $\zeta$.

It is curious that in our assays with NGF present, $\mathrm{PKC \imath} \mathrm{KI}$ showed a somewhat similar ability as $\mathrm{PKCl}$ WT to increase neuronal characteristics in the cells in which it was expressed. These results cannot be attributed to gross overexpression of these proteins since there was a lack of increase in overall $\mathrm{PKCl}$ levels in these cell lines (in Figure 1) and no change to $\mathrm{PKCl}$ activity. In fact, it is interesting that there was no observable increase in the abundance of the protein in the $\mathrm{PKCl}$ WT and $\mathrm{KI}$ cell lines despite the exogenous expression. It may be that PC12 cells (and perhaps other cell types) are sensitive to the abundance of $\mathrm{PKC} \mathrm{r}$ protein and may down-regulate endogenous $\mathrm{PKC} \mathrm{r}$ to compensate for the exogenously expressed $\mathrm{PKCl}$. We were unable to determine the ratio of exogenous to endogenous $\mathrm{PKCr}$ to verify this supposition. However, if true, this may suggest that the effects seen in the $\mathrm{PKC \imath} \mathrm{KI}$ cell line are due to replacement of normal $\mathrm{PKC \imath}$ with a defective $\mathrm{PKCl}$. However, this would not explain why expression of $\mathrm{PKCl}$ WT would have similar and even more potent effect than $\mathrm{PKC \imath} \mathrm{KI}$ or why no change in overall $\mathrm{PKCl}$ activity was observed among the cell lines.

It is notable that in the absence of NGF treatment, only the PKCi WT cell line showed a decrease of neuroendocrine function, as assayed by tyrosine hydroxylase levels. Also, although in NGF-treated PC12 cells expression of $\mathrm{PKC \imath} \mathrm{KI}$ led to a more neuronal phenotype, it was much less efficient than $\mathrm{PKCl}$ WT at down-regulating neuroendocrine characteristics (i.e., tyrosine hydroxylase, as seen in Figure 4). Thus, it may be that $\mathrm{PKCl}$ kinase activity is important in suppressing neuroendocrine differentiation, but not so much for promoting the early steps of neuronal differentiation. However, the results presented here imply that these are separable processes and that if both must occur for neuronal differentiation, both kinase and non-kinase activities of $\mathrm{PKC}$ may be at play at the start of determining a neuronal cell fate. The data also point to the notion that NGF treatment triggers pro-neuronal signal transduction pathways in PC12 cells that are impinged upon by the exogenous $\mathrm{PKC} \mathrm{t}$ proteins in some manner that may not depend on kinase activity, possibly via its effects of $\mathrm{PKC} \zeta$ activity.

Since aPKC activities in neuronal differentiation may rely on its ability to interact with key effectors of cytoskeleton dynamics and morphogenesis, we attempted to determine whether there was some difference in these interactions that could account for our observations, focusing on subsets of the PKCl/PAR-6/PAR-3/Cdc42 complexes [25] [26]. Our co-immunoprecipitation results lend themselves to the possibility that the PKC1/PAR6B interaction, and perhaps the minority PKC $/ \mathrm{PAR}-6 / \mathrm{PAR}-3$ complex, may underlie some of the observations contained within this study, although the mechanism may not be clear at present. Note that we did not observe any differences among our cell lines in PAR-6 binding to PKC $\zeta$ (data not shown), ruling out this possibility. We also did not detect any differences in PAR-3 phosphorylation among our cell lines (data not shown), precluding any obvious roles of this aPKC effector.

The aPKC/PAR-6 complex has been reported to bind to the activated form of Cdc42 [25] [26], which mediates actin polymerization and has been shown to be important for neurite outgrowth [28], especially with PC12 cells grown on laminin [29]. Thus, we were surprised that $\mathrm{Cdc} 42$ was not found in $\mathrm{PKC} \mathrm{i}$ immunoprecipitates, in spite of the increased neurite formation seen upon PKCı WT and KI expression. However, aPKC/PAR-6 also binds to a number of other signaling molecules that have been implicated in cell polarization and neuronal development (reviewed in [30]) that may be more important for the phenomena described here. Alternatively, it could be that the effects of WT and $\mathrm{KI} P K C \imath$ on the PKCl/PAR-6/PAR-3/Cdc42 complex or its subsets are either subtle or may be localized to specific regions of the cells such that they are undetectable by our assays.

It is intriguing that expression of $\mathrm{PKCl}$ CAT, which is constitutively active and did not bind to PAR-6 or PAR-3, did have any effect in the assays used here. It was noted that levels of $\mathrm{PKCl} \mathrm{CAT}$ were lower than $\mathrm{PKCl}$ WT and KI, however it was expected that its constitutively active status would compensate for its lower abundance, which did not occur. It is likely that PAR-6 and PAR-3 binding plays a central role in aPKC functions in cell determination, such that expression of the aPKC catalytic domain is insufficient for its neuronal-promoting functions. Along those lines, it is interesting that the greatest pro-neuronal effects in the majority of assays here 
were observed with the PKCı WT cell line, which did have greatest amount of expression. This may suggest that the endogenous $\mathrm{PKC}$ protein is somehow different from the exogenous protein in some manner (although overall cellular $\mathrm{PKC} \mathrm{C}$ kinase activity is unaffected) such that levels of the exogenous protein are the key factor mediating these results. We do not preclude the notion that the HA epitope tag on the C-terminal renders the $\mathrm{PKCl}$ protein defective in some way that does not impinge on overall $\mathrm{PKC \imath}$ kinase activity. Given that the C-terminus of aPKC has been shown to have key interactions that affect its function [31] [32], it may be that the HA tag interferes with these in some way. However, there may be other subtle differences between the endogenous and exogenous $\mathrm{PKC} \mathrm{C}$ proteins, such as temporal or spatial differences in expression that may also lead to the observed effects.

\section{Conclusion}

The supposition that the exogenous $\mathrm{PKCl}$ WT and $\mathrm{KI}$ are defective in some manner does not provide a simple explanation for the negative effect of $\mathrm{PKC \imath} \mathrm{WT}$ and $\mathrm{KI}$ on $\mathrm{PKC} \zeta$ kinase activity. A search of the literature did not find any reported instances of $\mathrm{PKCl}$ expression affecting $\mathrm{PKC} \zeta$ function. Moreover, the two isoforms are considered functionally equivalent, except for a reported inhibitor that affects $\mathrm{PKCl}$ and not $\mathrm{PKC} \zeta$ [33]. It is possible that the negative effect on $\mathrm{PKC} \zeta$ is indirect, resulting from some consequence of $\mathrm{PKCl}$ expression. It is very interesting that the ability of exogenous $\mathrm{PKCl}$ to promote neuronal characteristics inversely mirrors the effect on $\mathrm{PKC} \zeta$ activity, with $\mathrm{PKCl}$ WT cells showing the greatest inhibition of $\mathrm{PKC} \zeta$ and with $\mathrm{PKCl} \mathrm{KI}$ having a similar, but slightly less potent effect. The concurrency of these findings would suggest that our cell systems have perturbed some balance or interplay between the two aPKC isoforms. While a clear mechanistic explanation for why exogenous $\mathrm{PKCl}$ expression would affect $\mathrm{PKC} \zeta$ activity is not immediately apparent, it is possible that a subtle difference in localization or binding partners of the exogenous $\mathrm{PKC \imath}$ may cause a redistribution or sequestration of these factors from $\mathrm{PKC} \zeta$, preventing its activation. Clearly, further research is needed to investigate the interplay between the two aPKC isoforms as it relates to neuronal differentiation.

\section{Acknowledgements}

We thank Dr. Jae-Won Soh (Inha University, Korea) for generously providing vectors directing expression of HA-tagged wild-type and mutant forms of both PKC iota. We also thank Dr. Benjamin Weeks (Adelphi University) for discussion and for guiding us in the use of PC12 cells and neurite outgrowth assays.

Research reported in this publication was supported by the National Cancer Institute of the National Institutes of Health [award number R15CA121992].

\section{References}

[1] Nishizuka, Y. (1995) Protein Kinase C and Lipid Signaling for Sustained Cellular Responses. The FASEB Journal, 9, 484-496.

[2] Newton, A.C. (2010) Protein Kinase C: Poised to Signal. American Journal of Physiology Endocrinology and Metabolism, 298, E395-E402. http://dx.doi.org/10.1152/ajpendo.00477.2009

[3] Rosse, C., Linch, M., Kermorgant, S., Cameron, A.J., Boeckeler, K. and Parker, P.J. (2010) PKC and the Control of Localized Signal Dynamics. Nature Reviews Molecular Cell Biology, 11, 103-112. http://dx.doi.org/10.1038/nrm2847

[4] Izumi, Y., Hirose, T., Tamai, Y., Hirai, S., Nagashima, Y., Fujimoto, T., et al. (1998) An Atypical PKC Directly Associates and Colocalizes at the Epithelial Tight Junction with ASIP, a Mammalian Homologue of Caenorhabditis Elegans Polarity Protein PAR-3. Journal of Cell Biology, 143, 95-106. http://dx.doi.org/10.1083/jcb.143.1.95

[5] Shi, S.H., Jan, L.Y. and Jan, Y.N. (2003) Hippocampal Neuronal Polarity Specified by Spatially Localized mPar3/ mPar6 and PI 3-Kinase Activity. Cell, 112, 63-75. http://dx.doi.org/10.1016/S0092-8674(02)01249-7

[6] Nishimura, T., Yamaguchi, T., Kato, K., Yoshizawa, M., Nabeshima, Y., Ohno, S., et al. (2005) PAR-6-PAR-3 Mediates Cdc42-Induced Rac Activation through the Rac GEFs STEF/Tiam1. Nature Cell Biology, 7, 270-277. http://dx.doi.org/10.1038/ncb1227

[7] Shi, S.H., Cheng, T., Jan, L.Y. and Jan, Y.N. (2004) APC and GSK-3beta Are Involved in mPar3 Targeting to the Nascent Axon and Establishment of Neuronal Polarity. Current Biology, 14, 2025-2032. http://dx.doi.org/10.1016/j.cub.2004.11.009

[8] Greene, L.A.and Tischler, A.S. (1976) Establishment of a Noradrenergic Clonal Line of Rat Adrenal Pheochromocy- 
toma Cells Which Respond to Nerve Growth Factor. Proceedings of the National Academy of Sciences USA, 73, 24242428. http://dx.doi.org/10.1073/pnas.73.7.2424

[9] Soh, J.W., Mao, Y., Liu, L., Thompson, W.J., Pamukcu, R. and Weinstein, I.B. (2001) Protein Kinase G Activates the JNK1 Pathway via Phosphorylation of MEKK1. Journal of Biological Chemistry, 276, 16406-16410. http://dx.doi.org/10.1074/jbc.C100079200

[10] Soh, J.W. and Weinstein, I.B. (2003) Roles of Specific Isoforms of Protein Kinase c in the Transcriptional Control of Cyclin D1 and Related Genes. Journal of Biological Chemistry, 278, 34709-34716. http://dx.doi.org/10.1074/jbc.M302016200

[11] Naviaux, R.K., Costanzi, E., Haas, M. and Verma, I.M. (1996) The pCL Vector System: Rapid Production of HelperFree, High-Titer, Recombinant Retroviruses. Journal of Virology, 70, 5701-5705.

[12] Bangiyeva, V., Rosenbloom, A., Alexander, A., Isanova, B., Popko, T. and Schoenfeld, A. (2009) Differences in Regulation of Tight Junctions and Cell Morphology between VHL Mutations from Disease Subtypes. BMC Cancer, 9, 229. http://dx.doi.org/10.1186/1471-2407-9-229

[13] Reissmann, E., Ernsberger, U., Francis-West, P.H., Rueger, D., Brickell, P.M. and Rohrer, H. (1996) Involvement of Bone Morphogenetic Protein-4 and Bone Morphogenetic Protein-7 in the Differentiation of the Adrenergic Phenotype in Developing Sympathetic Neurons. Development, 122, 2079-2088.

[14] Peng, I., Binder, L.I. and Black, M.M. (1985) Cultured Neurons Contain a Variety of Microtubule-Associated Proteins. Brain Research, 361, 200-211. http://dx.doi.org/10.1016/0006-8993(85)91290-9

[15] Rossino, P., Gavazzi, I., Timpl, R., Aumailley, M., Abbadini, M., Giancotti, F., et al. (1990) Nerve Growth Factor Induces Increased Expression of a Laminin-Binding Integrin in Rat Pheochromocytoma PC12 Cells. Experimental Cell Research, 189, 100-108. http://dx.doi.org/10.1016/0014-4827(90)90262-9

[16] Dotti, C.G., Sullivan, C.A. and Banker, G.A. (1988) The Establishment of Polarity by Hippocampal Neurons in Culture. Journal of Neuroscience, 8, 1454-1468.

[17] Ludin, B. and Matus, A. (1993) The Neuronal Cytoskeleton and Its Role in Axonal and Dendritic Plasticity. Hippocampus, 3, 61-71.

[18] Caceres, A., Mautino, J. and Kosik, K.S. (1992) Suppression of MAP2 in Cultured Cerebellar Macroneurons Inhibits Minor Neurite Formation. Neuron, 9, 607-618. http://dx.doi.org/10.1016/0896-6273(92)90025-9

[19] Sharma, N., Kress, Y. and Shafit-Zagardo, B. (1994) Antisense MAP-2 Oligonucleotides Induce Changes in Microtubule Assembly and Neuritic Elongation in Pre-Existing Neurites of Rat Cortical Neurons. Cell Motility and the Cytoskeleton, 27, 234-247. http://dx.doi.org/10.1002/cm.970270305

[20] Coleman, E.S. and Wooten, M.W. (1994) Nerve Growth Factor-Induced Differentiation of PC12 Cells Employs the Pma-Insensitive Protein Kinase C-Zeta Isoform. Journal of Molecular Neuroscience, 5, 39-57. http://dx.doi.org/10.1007/BF02736693

[21] Wooten, M.W., Seibenhener, M.L., Zhou, G., Vandenplas, M.L. and Tan, T.H. (1999) Overexpression of Atypical PKC in PC12 Cells Enhances NGF-Responsiveness and Survival through an NF-KappaB Dependent Pathway. Cell Death and Differentiation, 6, 753-764. http://dx.doi.org/10.1038/sj.cdd.4400548

[22] Gschwendt, M., Dieterich, S., Rennecke, J., Kittstein, W., Mueller, H.J. and Johannes, F.J. (1996) Inhibition of Protein Kinase C Mu by Various Inhibitors. Differentiation from Protein Kinase C Isoenzymes. FEBS Letters, 392, 77-80. http://dx.doi.org/10.1016/0014-5793(96)00785-5

[23] Nagai-Tamai, Y., Mizuno, K., Hirose, T., Suzuki, A. and Ohno, S. (2002) Regulated Protein-Protein Interaction between aPKC and PAR-3 Plays an Essential Role in the Polarization of Epithelial Cells. Genes to Cells, 7, 1161-1171. http://dx.doi.org/10.1046/j.1365-2443.2002.00590.x

[24] Suzuki, A., Yamanaka, T., Hirose, T., Manabe, N., Mizuno, K., Shimizu, M., et al. (2001) Atypical Protein Kinase C Is Involved in the Evolutionarily Conserved Par Protein Complex and Plays a Critical Role in Establishing EpitheliaSpecific Junctional Structures. Journal of Cell Biology, 152, 1183-1196. http://dx.doi.org/10.1083/jcb.152.6.1183

[25] Joberty, G., Petersen, C., Gao, L. andMacara, I.G. (2000) The Cell-Polarity Protein Par6 Links Par3 and Atypical Protein Kinase C to Cdc42. Nature Cell Biology, 2, 531-539. http://dx.doi.org/10.1038/35019573

[26] Lin, D., Edwards, A.S., Fawcett, J.P., Mbamalu, G., Scott, J.D. and Pawson, T. (2000) A Mammalian PAR-3-PAR-6 Complex Implicated in Cdc42/Rac1 and aPKC Signalling and Cell Polarity. Nature Cell Biology, 2, 540-547. http://dx.doi.org/10.1038/35019582

[27] Zhou, J., Fariss, R.N. and Zelenka, P.S. (2003) Synergy of Epidermal Growth Factor and 12(S)-Hydroxyeicosatetraenoate on Protein Kinase C Activation in Lens Epithelial Cells. Journal of Biological Chemistry, 278, 5388-5398. http://dx.doi.org/10.1074/jbc.M209695200

[28] Daniels, R.H., Hall, P.S. and Bokoch, G.M. (1998) Membrane Targeting of p21-Activated Kinase 1 (PAK1) Induces 
Neurite Outgrowth from PC12 Cells. EMBO Journal, 17, 754-764. http://dx.doi.org/10.1093/emboj/17.3.754

[29] Weston, C.A., Anova, L., Rialas, C., Prives, J.M. and Weeks, B.S. (2000) Laminin-1 Activates Cdc42 in the Mechanism of Laminin-1-Mediated Neurite Outgrowth. Experimental Cell Research, 260, 374-378.

http://dx.doi.org/10.1006/excr.2000.5024

[30] Goldstein, B. andMacara, I.G. (2007) The PAR Proteins: Fundamental Players in Animal Cell Polarization. Developmental Cell, 13, 609-622. http://dx.doi.org/10.1016/j.devcel.2007.10.007

[31] Balendran, A., Biondi, R.M., Cheung, P.C., Casamayor, A., Deak, M. and Alessi, D.R. (2000) A 3-PhosphoinositideDependent Protein Kinase-1 (PDK1) Docking Site Is Required for the Phosphorylation of Protein Kinase Czeta (PKCzeta) and PKC-Related Kinase 2 by PDK1. Journal of Biological Chemistry, 275, 20806-20813. http://dx.doi.org/10.1074/jbc.M000421200

[32] Wang, G., Krishnamurthy, K., Umapathy, N.S., Verin, A.D. and Bieberich, E. (2009) The Carboxyl-Terminal Domain of Atypical Protein Kinase C Zeta Binds to Ceramide and Regulates Junction Formation in Epithelial Cells. Journal of Biological Chemistry, 284, 14469-14475. http://dx.doi.org/10.1074/jbc.M808909200

[33] Pillai, P., Desai, S., Patel, R., Sajan, M., Farese, R., Ostrov, D., et al. (2011) A Novel PKC-Iota Inhibitor Abrogates Cell Proliferation and Induces Apoptosis in Neuroblastoma. International Journal of Biochemistry and Cell Biology, 43, 784-794. http://dx.doi.org/10.1016/j.biocel.2011.02.002 